\title{
Managing Chronic Disease in Ontario Primary Care: The Impact of Organiza- tional Factors
}

Grant M. Russell, MBBS, FRACGP, MFM, $P b D^{1,2}$

Simone Dabrouge, $M S^{1}$

William Hogg, MSc, MClSc, MD, FCFP $P^{1-3}$

Robert Geneau, PbD ${ }^{1,2}$

Laura Muldoon, MD, MPH, FCFP $P^{1,2}$

Meltem Tuna, $P b D^{1}$

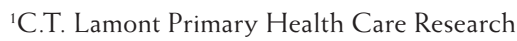
Centre, Élisabeth Bruyère Research Institute, Ottawa, Ontario, Canada

${ }^{2}$ Department of Family Medicine, University of Ottawa, Ottawa, Ontario, Canada

${ }^{3}$ Institute of Population Health, University of Ottawa, Ottawa, Ontario, Canada

\begin{abstract}
PURPOSE New approaches to chronic disease management emphasize the need to improve the delivery of primary care services to meet the needs of chronically ill patients. This study (1) assessed whether chronic disease management differed among 4 models of primary health care delivery and (2) identified which practice organizational factors were independently associated with high-quality care.
\end{abstract}

METHODS We undertook a cross-sectional survey with nested qualitative case studies ( 2 practices per model) in 137 randomly selected primary care practices from 4 delivery models in Ontario Canada: fee for service, capitation, blended payment, and community health centers (CHCs). Practice and clinician surveys were based on the Primary Care Assessment Tool. A chart audit assessed evidence-based care delivery for patients with diabetes, congestive heart failure, and coronary artery disease. Intermediate outcomes were calculated for patients with diabetes and hypertension. Multiple linear regression identified those organizational factors independently associated with chronic disease management.

RESULTS Chronic disease management was superior in CHCs. Clinicians in CHCs found it easier than those in the other models to promote high-quality care through longer consultations and interprofessional collaboration. Across the whole sample and independent of model, high-quality chronic disease management was associated with the presence of a nurse-practitioner. It was also associated with lower patient-family physician ratios and when practices had 4 or fewer full-time-equivalent family physicians.

CONCLUSIONS The study adds to the literature supporting the value of nursepractitioners within primary care teams and validates the contributions of Ontario's CHCs. Our observation that quality of care decreased in larger, busier practices suggests that moves toward larger practices and greater patientphysician ratios may have unanticipated negative effects on processes of care quality.

Ann Fam Med 2009;7:309-318. doi:10.1370/afm.982.

\section{INTRODUCTION}

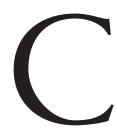
hronic health conditions are a substantial challenge to global health. ${ }^{1}$ By 2020 they will account for $73 \%$ of all deaths and $60 \%$ of the global burden of disease. ${ }^{2-5}$ Canada's experience matches that of much of the developed world, where in the next decade deaths caused by chronic diseases will increase by $15 \%{ }^{6}$ The growing burden of chronic diseases threatens the sustainability of health care systems. ${ }^{7.8}$ In the United States, for example, the annual economic effect on the US economy of the most common chronic diseases is more than $\$ 1$ trillion and could reach nearly $\$ 6$ trillion by the middle of the century. ${ }^{4}$ Canada stands to lose $\$ 9$ billion in the next decade from premature deaths caused by heart disease, stroke, and diabetes. ${ }^{6}$ 
Policy makers have become increasingly interested in the potential of high-quality primary care to help deal with the chronic disease challenge. Primary care is well positioned to have an important impact on outcomes of care for patients with chronic conditions. ${ }^{9}$ There are, however, important variations in the delivery of chronic disease management programs and services in primary care.$^{10,11}$ Recent studies suggest that the way chronic disease management is delivered in general practice is highly influenced by organizational factors. ${ }^{12,13}$ Various studies have suggested that highquality chronic disease management can be promoted by financial incentives, capitated payment structures, improved Internet technology infrastructure, and the wider use of nonmedical health care professionals. ${ }^{14-16}$

In Canada, several provinces are in the process of redesigning their primary care system with the clear purpose of improving chronic illness care. ${ }^{10}$ This report originates from a mixed methods study, Comparison of Models of Primary Health Care in Ontario, funded by the Ontario Ministry of Health and Long Term Care. The study was designed to describe and compare the structure and process of care within 4 primary health care delivery models in Ontario, Canada: fee for service (FFS), family health networks (FHNs), health service organizations (HSOs), and community health centers (CHCs). ${ }^{11}$ From 2004 through 2006 practices operating within these 4 models were responsible for delivering primary care to most of the Ontario population. Table 1 displays these models, as well as the family health groups (FHGs) to which most practices in the FFS group eventually transitioned, and their essential characteristics. ${ }^{17-19}$

In this article we address 2 questions: (1) does chronic disease management differ between the 4 models of primary health care delivery in Ontario, and

Table 1. Comparing the Features of the Models in 2005-2006

\begin{tabular}{|c|c|c|c|c|c|}
\hline Characteristic & $\begin{array}{l}\text { Community Health } \\
\text { Center (CHC) }\end{array}$ & $\begin{array}{l}\text { Fee for } \\
\text { Service } \\
\text { (FFS) }\end{array}$ & $\begin{array}{l}\text { Family Health } \\
\text { Groups (FHG) }\end{array}$ & $\begin{array}{l}\text { Family Health } \\
\text { Network (FHN) }\end{array}$ & $\begin{array}{l}\text { Health Service } \\
\text { Organization } \\
\text { (HSO) }\end{array}$ \\
\hline Year introduced & 1970s & - & 2004 & 2001 & 1970 s \\
\hline Group size & $\begin{array}{l}\text { Group practice, size } \\
\text { unspecified }\end{array}$ & 1 Physician & Minimum 3 & Minimum 3 & Minimum 3 \\
\hline $\begin{array}{l}\text { Physician } \\
\text { remuneration }\end{array}$ & Salary & FFS & $\begin{array}{l}\text { FFS and } \\
\text { incentives }\end{array}$ & $\begin{array}{l}\text { Capitation }{ }^{b} \text { with a } \\
\text { 10\% FFS compo- } \\
\text { nent, and incentives }\end{array}$ & $\begin{array}{l}\text { Capitation }{ }^{b} \text { and } \\
\text { incentives }\end{array}$ \\
\hline \multirow[t]{2}{*}{ Patient enrollment } & Required & Not required & Required & Required & Required \\
\hline & No roster size limit & & $\begin{array}{l}\text { No roster size } \\
\text { limit }\end{array}$ & $\begin{array}{l}\text { Disincentive to enroll } \\
>2,400^{c}\end{array}$ & $\begin{array}{l}\text { Disincentive to enroll } \\
>2,400^{c}\end{array}$ \\
\hline \multirow[t]{3}{*}{ Access } & \multirow{3}{*}{$\begin{array}{l}\text { No specified } \\
\text { requirements }\end{array}$} & \multirow{3}{*}{$\begin{array}{l}\text { No specified } \\
\text { requirements }\end{array}$} & THAS & THAS & THAS \\
\hline & & & Extended hours ${ }^{e}$ & Extended hours ${ }^{d}$ & Extended hours ${ }^{d}$ \\
\hline & & & & Access bonuse & Access negation ${ }^{f}$ \\
\hline Multidisciplinarityg & Extensive & None & None & Some & Some \\
\hline $\begin{array}{l}\text { Assistance for informa- } \\
\text { tion technology }\end{array}$ & Some & None & None & Yes & None \\
\hline Objectives/priorities & $\begin{array}{l}\text { Responsiveness to popu- } \\
\text { lation needs, multidis- } \\
\text { ciplinarity, prevention, } \\
\text { focus on underserved, } \\
\text { community governed }{ }^{18}\end{array}$ & - & Accessibility ${ }^{19}$ & $\begin{array}{l}\text { Accessibility, compre- } \\
\text { hensiveness, doctor- } \\
\text { nurse collaboration, } \\
\text { use of technology }\end{array}$ & $\begin{array}{l}\text { Responsiveness to } \\
\text { population needs, } \\
\text { multidisciplinarity, } \\
\text { health promotion, } \\
\text { cost effectiveness } 20\end{array}$ \\
\hline
\end{tabular}

Adapted from https://www.oma.org/PC/PCRComparisonJan0807.pdf (PCRComparisonJan0807.pdf).

THAS = Telephone Health Advisory Service, a patient telephone advisory system for which physicians are required to provide on-call services 24 hours a day, 7 days a week.

a Late in 2004, the Ontario Ministry of Health (MOH) created a new model of care, the FHG, to which FFS practices could transition. A family health group (FHG) is a collaborative comprehensive primary care delivery model involving 3 or more physicians practicing together. These physicians need not be located in the same physical office space, but must be within reasonable distance of each other. FFS practices converted to this new model quickly, so that by early 2006 most FFS practices had become FHGs, and it became evident that the great majority would transition by the year end.

${ }^{b}$ Under capitation remuneration, family physicians received a fixed monthly fee per patient enrolled, independent of the number of visits made to the practice by that patient. The capitation fee is based on the enrolled patient sex and age. FHN physicians receive an additional $10 \%$ of the FFS structure for each visit. The latter is intended to allow better monitoring of services delivered. In 2008 all HSO were converted to family health organizations. Under that model, the practices today also receive $10 \%$ of the FFS structure for each visit.

c The base capitation rate is reduced to $50 \%$ for patients enrolled to a clinician with a practice size exceeding 2,400.

${ }^{d}$ Each physician is required to provide at least 1, 3-hour session outside regular hours (evening/weekend) per week (up to 5 sessions per group/network/organization).

e An incentive bonus reduced in relation to number of visits patients make to nonspecialists outside the FHN.

${ }^{\mathrm{f}} \mathrm{A}$ penalty incurred from the capitation fee for visits patients make to nonspecialists outside the FHN. Today, HSO practices are eligible for the access bonus are not subject to negation.

${ }^{9}$ Multidisciplinarity refers to the presence of allied health professionals (eg, physiotherapist, social worker, and pharmacist), excluding nursing staff, but including nurse-practitioners. 
the ability to detect a difference in another outcome measure: disease prevention. The study was powered to detect a difference of 0.5 standard deviation in the disease prevention score, with an intraclass correlation of 0.2 , an $\alpha$ value of .05 , and a $\beta$ value of 0.20 . Power analysis was performed for the overall chronic disease management.

The chronic disease management score was computed through use of the G-power program (a free statistical program developed by Franz Faul,Uni Kiel,Germany: http://www.psycho.uni-duesseldorf. de/abteilungen/aap/gpower3/). We calculated the difference between models that could be detected with an $80 \%$ power to be $12 \%$.

\section{Data Analysis}

Data were analyzed using SPSS-PC version 15.0 (SPSS Inc, Chicago, Illinois). The unit of analysis was the model for the first question (comparing the models) and the practice for the second question (ascertaining organizational factors associated with better chronic disease management.)

\section{Description of the Models}

Descriptive profiles of the models' characteristics assessed intermodel variability. Patient, clinician, and practice factor associations with the chronic disease management score were evaluated individually using linear regression analyses. Linearity of continuous variables was verified.

\section{Comparison of Models}

Differences in the models' chronic disease management scores were first assessed through analyses of variance. Linear and logistic regressions were used to examine individual indicators and secondary clinical outcomes. To adjust for the influence of patient and clinician characteristics on the models' differences in score, 2 separate multiple linear regressions were performed (each controlled for patient characteristics and rurality; the second added a control for clinician characteristics).

\section{Organizational Factors}

Organizational factors (clinician and practice characteristics) associated with performance of chronic disease management were identified by applying multiple linear regression analysis with forward selection (entry of $P=.10$ and exit of $P=.15$ ) while controlling for patient characteristics. To evaluate the transferability of associations across models, the findings were applied to each model individually.

For the qualitative analysis, interviews were taperecorded, transcribed verbatim, then coded and analyzed with the support of N6 software. ${ }^{28}$ We used a coding tree informed by the literature on primary care organizations, which was then refined through an iterative process using an open coding strategy. ${ }^{29}$ Subsequent analysis involved axial and selected coding to explore interconnections between existing categories and subcategories. ${ }^{30}$ Finally, we used an immersion/crystallization approach ${ }^{31}$ to identify and articulate the themes and patterns emerging from the empirical dataset.

\section{RESULTS}

Practice and patient survey response rates ranged between $23 \%$ to $69 \%$ and $74 \%$ to $85 \%$, respectively. Secondary analysis of province-wide health administrative databases showed that the physicians from each model participating in the study were similar to all physicians practicing in that model in Ontario. Four practice patterns could also be evaluated in FFS and FHN practices. These patterns were found to differ by less $25 \%$ in 7 of 8 comparisons (results not shown).

\section{Descriptive and Bivariate Analyses}

Data were collected from 137 practices and 363 health clinicians. We interviewed 46 clinicians and 22 patients. Among the 4,108 patients included in the chart abstractions, $514(12.5 \%)$ had at least 1 chronic condition and are included in the chronic disease management score. A further 899 charts were included from patients with hypertension.

Table 3 displays the models in terms of patient, clinician, and practice characteristics and indicates bivariate association with the chronic disease management score. Adherence to recommended care was $6 \%$ higher in men. Performance increased with age until approximately 65 to 70 years, after which it dropped (data not shown).

\section{Comparison of Models}

After we adjusted the regression analysis for potential confounding factors, CHCs had higher overall performance of chronic disease management (by 10\% to $15 \%$ ), a result largely explained by their better performance in evidence-based processes associated with diabetic care (Table 4). No differences between models were detected for the clinical intermediate outcomes except for diastolic blood pressure readings, which were significantly lower in HSO patients.

\section{Organizational Factors Associated With Chronic Disease Management Performance}

Table 5 shows the organizational factors independently associated with chronic disease management scores after adjusting for significant patient factors. The presence of a nurse-practitioner was associated with a 
$10 \%$ absolute increase in disease management scores, whereas larger practices (with more than 4 full-timeequivalent family physicians) had a $7 \%$ lower score than smaller practices. Higher patient load per physician (number of patients per family physician) was also associated with lower scores. The relationship was linear, with each additional 1,000 patients being associated with a $3 \%$ drop in the score. The multivariate model accounted for $9 \%\left(R^{2}=.09\right)$ of score variability. In this multivariate equation, the addition of the model variables did not add significant explanatory value, suggesting that much of the impact of the model variable was captured in the 3 predictive factors.

Table 6 shows a stratified analysis by model. The results indicate that, with the exception of the patient load variable, which appears to be driven by its effect within FFS and HSO practices, the independent variables associated with performance of chronic disease management were consistent across models. Larger practices were associated with lower levels of care in $\mathrm{CHC}$, FFS, and HSO practices, but not in FHNs. The presence of a nurse-practitioner in a practice was associated with approximately $6 \%$ better performance.

The qualitative findings shed light on some of the care processes that facilitate effective chronic disease management. First, there was a general consensus among clinicians that longer consultations translate into better care for chronically ill patients. CHC physicians and nurse-practitioners seemed less likely than those working in other models to feel time-challenged.

Table 3. Patient, Clinician, and Practice Characteristics by Care Model

\begin{tabular}{|c|c|c|c|c|c|c|}
\hline \multirow[b]{2}{*}{ Characteristic } & \multicolumn{4}{|c|}{ Practice Model } & \multicolumn{2}{|c|}{ Association With CDM ${ }^{a}$} \\
\hline & $\mathrm{CHC}$ & FFS & FHN & HSO & $\beta$ & $P$ Value \\
\hline Patients included in CDM score & 120 & 115 & 138 & 141 & - & - \\
\hline Diabetes, $\mathrm{n}$ & 82 & 69 & 80 & 82 & - & - \\
\hline Coronary artery disease, $n$ & 50 & 57 & 72 & 84 & - & - \\
\hline Congestive heart failure, $n$ & 8 & 15 & 15 & 19 & - & - \\
\hline Hypertension, n & 201 & 221 & 257 & 236 & - & - \\
\hline Chronic diseases, average, $\mathrm{n}^{\mathrm{b}}$ & 1.8 & 1.8 & 1.9 & 2.0 & 0.043 & .019 \\
\hline Age, $y^{c}$ & 59.6 & 62.6 & 63.8 & 65.1 & 0.0022 & .016 \\
\hline Sex, male, \% & 39 & 49 & 49 & 50 & 0.057 & .027 \\
\hline Practice profile $\mathbf{n}$ (\% response) & $35(69)$ & $35(23)$ & $35(37)$ & $32(49)$ & & \\
\hline Solo practices, \% & 0 & 26 & 37 & 38 & 0.0041 & .87 \\
\hline Practice size $>4$ family physicians, \% & 17 & 14 & 40 & 3 & -0.044 & .188 \\
\hline \multicolumn{7}{|l|}{ Practice full-time equivalent, $n$} \\
\hline Family physicians & 3.0 & 2.4 & 3.6 & 1.7 & -0.0039 & .50 \\
\hline Nurse-practitioners & 2.5 & 0.1 & 0.3 & 0.2 & 0.035 & .001 \\
\hline Nurses $^{d}$ & 2.7 & 0.6 & 1.9 & 1.0 & 0.012 & .19 \\
\hline Presence of nurse-practitioner, \% & 100 & 8.6 & 31.4 & 18.8 & 0.097 & $<.001$ \\
\hline No. of patients per family physician, $\times 1,000$ & 1.3 & 1.8 & 1.5 & 2.0 & -0.032 & .033 \\
\hline Booking time for routine visit, min & 25 & 13 & 14 & 14 & 0.0063 & .004 \\
\hline \multicolumn{7}{|l|}{ Setting } \\
\hline Hospital within $10 \mathrm{~km}$ & 71 & 85 & 94 & 84 & -0.031 & .35 \\
\hline Rurality index & 14.2 & 12.6 & 16.2 & 8.0 & -0.0010 & .16 \\
\hline Length of practice operation, y & 18.3 & 16.4 & 24.4 & 26.7 & 0.00029 & .80 \\
\hline \multicolumn{7}{|l|}{ Information technologies, \% } \\
\hline Electronic patient records & 29 & 14 & 57 & 44 & -0.021 & .44 \\
\hline Electronic reminder system & 26 & 14 & 46 & 28 & 0.036 & .19 \\
\hline Clinician profile, n & 182 & 58 & 81 & 42 & & \\
\hline Years since graduation, $\mathrm{n}$ & 19 & 22 & 23 & 29 & 0.0021 & .15 \\
\hline Female clinician, \% & 58 & 45 & 41 & 26 & -0.023 & .47 \\
\hline Foreign-trained clinician, \% & 9 & 17 & 3 & 14 & -0.0065 & .90 \\
\hline Clinicians with CFPC degree, \% & 79 & 85 & 78 & 68 & -0.0017 & .96 \\
\hline \multicolumn{7}{|c|}{$\begin{array}{l}\mathrm{CDM}=\text { chronic disease management; } \mathrm{CFPC}=\text { The College of Family Physicians of Canada; } \mathrm{CHC}=\text { community health center; } \mathrm{FSS}=\text { fee for service; FHN }=\text { family hea } \\
\text { network; } \mathrm{HSO}=\text { health service organization. }\end{array}$} \\
\hline $\begin{array}{l}\text { a Result of unadjusted regression analysis between CD } \\
\text { b Includes all charts in sample meeting criteria for dia } \\
\text { ' The relationship between CDM and age is best repre } \\
\text { d Includes registered practical nurses, nurses, and nur }\end{array}$ & $\begin{array}{l}\text { ore and each } \\
\text {, coronary ar } \\
\text { ed by the foll } \\
\text { assistants. }\end{array}$ & $\begin{array}{l}\text { iable separat } \\
\text { disease, cor } \\
\text { ng second-or }\end{array}$ & $\begin{array}{l}\text { tive hearth } \\
\text { equation: ag }\end{array}$ & $\begin{array}{l}\text { e, and hyper } \\
=0.027+\mathrm{ag}\end{array}$ & $\begin{array}{l}\text { n. } \\
=0.00019 .\end{array}$ & \\
\hline
\end{tabular}


...for diabetics to do the teaching that takes time, the amount of time you need to spend with those people is significant...here you have the fee structure set up where you are able to take that time... it is not a factory. It is not an assembly line. It's good health care (Nurse-practitioner, CHC).

Additionally, many CHC participants suggested that participation in a collaborative team forces more comprehensive and accurate charting. One CHC physician with a long experience in FFS settings noted:

...in a private practice you are the only person who sees the file, so nobody else has to be able to interpret what you have written...while here the charts are much more comprehensive. I am not saying that it is a better system than in a private practice, I just know that the files are not as complete maybe as they would be in a place like this (Family physician, $\mathrm{CHC}$ ).
Table 4. Chronic Disease Management Measures Across Models

\begin{tabular}{|c|c|c|c|c|c|}
\hline Measures & $\mathrm{CHC}$ & FFS & FHN & HSO & $P$ Value \\
\hline \multicolumn{6}{|l|}{ Process measures } \\
\hline \multicolumn{6}{|l|}{ Diabetes, \% } \\
\hline $\begin{array}{l}\text { Foot examination documented in } \\
\text { previous } 2 y\end{array}$ & 63 & 29 & 39 & 39 & $<.001^{\mathrm{a}}$ \\
\hline Eye examination in previous 2 y & 61 & 44 & 38 & 37 & $.005^{\mathrm{a}}$ \\
\hline ACEI/ARB in previous $2 \mathrm{y}$ & 71 & 64 & 65 & 73 & $.536^{a}$ \\
\hline $2 \mathrm{HbA}_{1 \mathrm{c}}$ tests in previous $1 \mathrm{y}$ & 73 & 57 & 54 & 48 & $.007^{a}$ \\
\hline Overall diabetes score & 69 & 52 & 53 & 54 & $<.001^{\mathrm{b}}$ \\
\hline \multicolumn{6}{|l|}{ Coronary artery disease, \% } \\
\hline Aspirin documented in previous $2 \mathrm{y}$ & 80 & 75 & 72 & 75 & $.81^{\mathrm{a}}$ \\
\hline$\beta$-Blocker documented in previous 2 y & 80 & 67 & 62 & 73 & $.18^{\mathrm{a}}$ \\
\hline Statin documented in previous 2 y & 76 & 81 & 64 & 76 & $.14^{\mathrm{a}}$ \\
\hline Overall coronary artery disease score & 79 & 74 & 66 & 75 & $.11^{\mathrm{b}}$ \\
\hline \multicolumn{6}{|l|}{ Congestive heart failure, $\%$} \\
\hline ACEI/ARB in previous $2 \mathrm{y}$ & 63 & 93 & 93 & 84 & $.17^{\mathrm{a}}$ \\
\hline$\beta$-Blocker in previous 2 y & 50 & 47 & 47 & 68 & $.51^{\mathrm{a}}$ \\
\hline Overall congestive heart failure score & 56 & 70 & 70 & 76 & $.56^{b}$ \\
\hline \multicolumn{6}{|l|}{$\begin{array}{l}\text { Overall chronic disease management } \\
\text { score, } \%\end{array}$} \\
\hline Total score, mean & 72 & 61 & 60 & 64 & $.003^{b}$ \\
\hline Unadjusted difference in score ${ }^{c}$ & Ref & $-11^{d}$ & $-12^{e}$ & $-8^{f}$ & \\
\hline Adjusted difference in scoreg & Ref & $-13^{e}$ & $-15^{e}$ & $-10^{d}$ & \\
\hline \multicolumn{6}{|l|}{$\begin{array}{l}\text { Outcome measures: } \\
\text { intermediate clinical outcome }\end{array}$} \\
\hline \multicolumn{6}{|l|}{ Diabetes } \\
\hline Target $\mathrm{HbA}_{1 \mathrm{c}} \% \%^{\mathrm{h}}$ & 56 & 54 & 61 & 55 & $.83^{\mathrm{a}}$ \\
\hline Last $\mathrm{HbA}_{1 \mathrm{c}}$ level, mean \% & 7.3 & 7.1 & 6.8 & 7.2 & $.23^{\mathrm{b}}$ \\
\hline \multicolumn{6}{|l|}{ Hypertension } \\
\hline Target blood pressure, $\%{ }^{i}$ & 38 & 40 & 39 & 44 & $.65^{\mathrm{a}}$ \\
\hline Systolic blood pressure, mean, $\mathrm{mm} \mathrm{Hg}$ & $138^{j}$ & 135.2 & 137 & 135.3 & $.055^{b}$ \\
\hline Diastolic blood pressure, mean, mm Hg & $81.2^{j}$ & $80.4^{k}$ & $80.1^{\mathrm{k}}$ & 76.7 & $.007^{b}$ \\
\hline
\end{tabular}

$\mathrm{ACEI} / \mathrm{ARB}=$ antiotensin-converting enzyme inhibitors/antiotensin receptor blockers; $\mathrm{CHC}=$ community health center; FFS = fee for service; FHN = family health network; HbA1c = hemoglobin A1c; $\mathrm{HSO}=$ health service organization.

Note: Values, unless otherwise stated, are expressed as percentage of charts on which the individual manoeuvre was noted.

a Generated from contingency table using Pearson $x^{2}$ statistic.

${ }^{b}$ Generated with analysis of variance.

c Result of regression analysis with only model dummy variables.

d $P<.01$ compared with $\mathrm{CHC}$ as reference.

e $P<.001$ compared with $\mathrm{CHC}$ as reference.

${ }^{f} \mathrm{P}<.05$ compared with $\mathrm{CHC}$ as a reference.

${ }^{g}$ Result of regression analysis with model dummy variables and adjusted for patient age and sex.

${ }^{h}$ Percentage of patients with $\mathrm{HbA}_{1 \mathrm{c}} \leq 7.0$

i Percentage of patients with average target blood pressure in previous 6 months. Target blood pressure was $130 / 80 \mathrm{~mm} \mathrm{Hg}$ for patients with diabetes and $140 / 90 \mathrm{~mm} \mathrm{Hg}$ for all others.

j $P<.05$ compared to $\mathrm{HSO}$ as reference.

k $P<.001$ compared to HSO as reference.
Of importance, $\mathrm{CHCs}$ had a degree of organizational readiness for changes aimed at improving diabetes care, particularly in their use of diabetes education and care teams. Nurse-practitioners were an important part of many of these teams, with their activities ranging from consultation-based primary care to the organization of chronic disease clinics. The contributions of diabetes nurse specialists, dietitians, and chiropodists are also valued by $\mathrm{CHC}$ physicians:

...because of the way the organization is set up, it can almost be set up so that the diabetes is managed with directives by the physician and all of that by the diabetes nurse. So she can increase their medication, she can advise them on what to do with their diabetes, so that helps a lot because then...that is one major chronic disease that can be cared for that I don't have to deal with. I can deal with whatever else, or I can deal with the more complicated issues of the diabetes.... We have a diet counselor who can help with patients with problems with weight, obesity, and the like. What else do we have? A chiropodist, so that helps with the foot problems. All of those help with the most complex patients, you can kind of help each other out on that. (Family physician, $\mathrm{CHC}$ ).

Physicians practicing in other models reported that they are only slowly starting to take advantage of system change related to diabetes care:

There is a special code that I can use for seeing diabetics... (since I began to use the code). I am starting to 


Table 5. Organizational Factors Independently Associated With
Chronic Disease Management
\begin{tabular}{lccc}
\hline Practice Profile Predictors & $\boldsymbol{\beta}$ & $\boldsymbol{P}$ Value & Confidence Interval \\
\hline Presence of nurse-practitioner & 0.101 & $<.001$ & 0.051 to 0.152 \\
Large practices $^{\mathrm{a}}$ & -0.067 & .040 & -0.13 to -0.003 \\
Patient load $^{\mathrm{b}}$ & -0.032 & .028 & -0.060 to -0.004 \\
\hline
\end{tabular}

Note: Results of regression model showing the impact of each factor on chronic disease management performance. The model is adjusted for patient age and sex.

a Practices hosting more than 4 family physicians.

${ }^{b}$ No. of patients per family physician $(\times 1,000)$.

\section{Table 6. Organizational Factors Independently Associated With Chronic Disease Management Across Models ( $\beta$ Represented Only)}

\begin{tabular}{lccccc}
\hline Practice Profile Predictors & Overall & CHC & FFS & FHN & HSO \\
\hline Presence of nurse-practitioner & 0.101 & $--^{\mathrm{a}}$ & 0.062 & 0.054 & 0.060 \\
Large practices $^{b}$ & -0.067 & -0.125 & -0.076 & 0.0042 & -0.087 \\
Patient loadc $^{c}$ & -0.032 & 0.021 & -0.069 & -0.0037 & -0.026 \\
\hline
\end{tabular}

$\mathrm{CHC}=$ Community Health Center; FFS = fee for service; $\mathrm{FHN}=$ family health network; $\mathrm{HSO}=$ health service organization.

Note: Results of regression model showing the impact of each factor on chronic disease management performance. The model is adjusted for patient age and sex.

a All participating CHCs hosted nurse-practitioners.

b Practices hosting more than 4 family physicians.

' No. of patients per family physician $\times 1,000$.

book longer visits for my diabetic patients in order to do those assessments, which is actually what we should have been doing, I wasn't really aware that there was such a comprehensive assessment doable. I guess I was aware but I just wasn't organized enough to do it (Family physician, FHN).

\section{DISCUSSION}

This study adds to the sparse literature comparing chronic disease management between differing models of primary care. It also offers insight into the organizational features within a primary care practice associated with high-quality care of chronic health conditions.

There are 2 key findings. First, we found evidencebased processes associated with high-quality chronic disease care to be most common in Ontario's CHCs. Second, across the whole sample, high-quality chronic care delivery was more likely with the presence of a nurse-practitioner. Quality of care decreased with patient load and in those practices with more than 4 full-time-equivalent family physicians. These factors outweighed any independent influence of model of care delivery.

Ontario's CHCs were established in the 1970s and were part of a broader Canadian initiative to respond to perceived problems in health service delivery. Unlike other models within our study, CHCs operate under community governance, pay physicians by salary, and combine clinical services with a range of integrated community programs. Several have implemented specific diabetes care programs. We found that measures of diabetic processes of care were higher in $\mathrm{CHCs}$, but that blood glucose control was not. With the exception of $\mathrm{HbA}_{1 \mathrm{c}}$ assessments, the processes measured in diabetes were related to the detection and prevention of end-organ damage rather than blood glucose control. Still, if the processes measures used to evaluate performance were an indicator of overall care, one may have expected improved intermediate outcomes in that population. Failure to observe a difference may relate to the gap between recommended care and patient compliance or response to such care.

CHCs based in the United States have been found to deliver a higher standard of care when compared with hospital outpatient clinics, and physician's offices. ${ }^{32,33}$ Patients rate them highly in service coordination, comprehensiveness, and community orientation. ${ }^{34}$ In our study, 2 of 3 organizational characteristics independently associated with quality chronic disease management processes (the presence of a nurse-practitioner and smaller patient-physician ratios) were characteristic of $\mathrm{CHC}$ practices.

Our findings add to the literature suggesting that nurse-practitioners have a positive effect on a number of aspects of primary care delivery. ${ }^{35,36}$ The presence of other clinical disciplines did not have a positive association with chronic disease management. Although there is evolving understanding of the benefits of, and processes associated with, nurse-practitioner-physician collaboration, ${ }^{37-39}$ the reasons underlying improved outcomes associated with nurse-practitioner involvement in primary care teams are unclear. There are several possibilities. First, a nurse-practitioner may help ease physician workload through taking over some duties usually performed by physicians. Second, nursepractitioners may affect performance through their involvement in delivering care through organized care management activities, such as diabetes clinics. Finally, it is feasible that the incorporation of a nurse-practitioner, particularly in the non-CHC practices, is a marker of practice-based organizational approaches toward changing the status quo. 
Professional organizations have been increasingly preoccupied with the impact of workforce shortages of primary care clinicians, in particular family physicians and nurses. Our data suggested that practices with smaller numbers of patients per clinician were more likely to provide higher care quality, principally in FFS, the model serving the largest population of Ontarians.

We found better chronic disease management in practices containing 4 or fewer family physicians-a finding consistent across each of the models. Although several US-based studies have found a modest direct correlation between the number of physicians and the quality of chronic care processes, ${ }^{40-42}$ recent British studies have found practice size to be only modestly, ${ }^{43}$ if at all, predictive of quality of care processes. ${ }^{44}$

Again, our cross-sectional design makes it difficult to be certain about the reasons behind the association between smaller practices and better chronic disease management. The finding, however, may be associated with unique features of Ontario primary care. Unlike overseas, physicians' assistants are unknown in Ontario, reducing the likelihood of the delegation of activities often found in larger practices. With the province only beginning the process of primary care reform, it may be that larger practices are yet to perceive sufficient incentives to initiate high-quality care processes. Accordingly, it may be that the potential economies of scale of larger practices may be outweighed by easier practice decision making in smaller practice sites.

Unlike others, ${ }^{32,40,45,46}$ we found no evidence that a practice's use of electronic medical records influenced the chronic disease management score. Similar findings in studies comparing chronic disease management in paper-based and electronic practices in the United States ${ }^{47}$ and Quebec ${ }^{48}$ suggest that although practice information systems can assist chronic disease management, using such systems is no guarantee of effective chronic disease care.

This cross-sectional study has a number of limitations. Our practice sample excluded practices in the far north of the province and was limited by a low response rate in FFS practices (23\%). Nevertheless, our FFS sample had a similar demographic profile to grouped data on all FFS practices within Ontario. Our assessment of chronic disease care excluded the consideration of chronic disease management in children and was restricted to the consideration of 3 conditions. Our outcome measures were ascertained by chart abstractions, well known to underestimate care processes through their inability to capture processes of care that are delivered, but not documented. This approach can also lead to a biased model comparison if differential charting practices exist across models, a parameter we did not measure. Even so, differences in the quality of care observed between models were not exclusively found in processes that are less likely to be documented. They were also found, for example, in the frequency of hemoglobin $\mathrm{A}_{1 \mathrm{c}}$ evaluation, suggesting that document bias alone could not explain the differences in the performance measured. Finally, whereas our assessment of practice factors potentially influencing quality of care was large, it was not comprehensive. For example, we did not collect data on the clinician's experience of, as well as characteristics of, the relationships with their patients or within team members.

\section{Implications for Policy and Practice}

Our data allowed us to evaluate chronic care outcomes in a province undergoing considerable primary care reform. The study adds to the evidence suggesting that the organization and makeup of the primary care team influences the delivery of care quality. Our findings add to the literature supporting the value of nurse-practitioners within primary care teams and validate the contributions of Ontario's CHCs. Further work should examine whether current moves toward larger practices and greater patient physician ratios may have unanticipated negative impacts on processes of quality care.

To read or post commentaries in response to this article, see it online at http://www.annfammed.org/cgi/content/full/7/4/309.

Key words: Primary health care; chronic disease; quality of health care

Submitted June 16, 2008; submitted, revised, September 30, 2008; accepted October 8, 2008.

Preliminary findings concerning the specific topic of this paper have been presented at several conferences: Geneau R, Dahrouge S, Russell $G$, et al. The organizational determinants of chronic disease management practices. Annual Meeting of the North American Primary Care Research Group. Vancouver, October 2007; Russell GM. Access and quality of clinical care: results from the Comparison of Models of Primary Care (COMPC) Study. Primary Health Care Research, Evaluation and Development Western Australia: Seminar, Como, Australia, December 2006; Russell GM, Dahrouge S, Hogg W, Kristjansson B. Does delivery model influence clinical quality? Interim findings from the Comparison of Models of Primary Care in Ontario study (paper), 34th NAPCRG Annual Meeting, Tucson, AZ, October 2006; Hogg W, Russell GM, Dahrouge $S$, et al. Results from the Comparison of Models of Primary Care in Ontario study (paper), 34th NAPCRG Annual Meeting, Tucson, AZ, October 2006.

Funding support: Funding for this research was provided by the Ontario Ministry of Health and Long-Term Care Primary Health Care Transition Fund.

Disclaimer: The views expressed in this report are the views of the authors and do not necessarily reflect those of the Ontario Ministry of Health and Long-Term Care.

Acknowledgments: The authors wish to acknowledge the assistance provided by Dr Enrique Soto in the preparation of this manuscript. 
Funding for this research was provided by the Ontario Ministry of Health and Long-Term Care Primary Health Care Transition Fund. The views expressed in this report are the views of the authors and do not necessarily reflect those of the Ontario Ministry of Health and LongTerm Care.

\section{References}

1. Dorland J. McColl MA, eds. Emerging Approaches to Chronic Disease Management in Primary Care. Ontario, Canada: McGill Queen's University Press; 2007.

2. Lopez AD, Mathers CD, Ezzati M, Jamison DT, Murray CJL. The Global Burden of Disease. Boston, MA: Harvard School of Public Health; 2007.

3. World Health Organization. Innovative Care for Chronic Conditions: Building Blocks for Action. Geneva: Noncommunicable Diseases and Mental Health, World Health Organization; 2002.

4. Devol R, Bedroussian, A. An Unhealthy America: The Economic Burden of Chronic Disease-Charting a New Course to Save Lives and Increase Productivity and Economic Growth. Santa Monica, CA: Milken Institute; 2007.

5. Joint WHO/FAO Expert Consultation. Diet, Nutrition and the Prevention of Chronic Diseases. 2003. http://www.who int/mediacentre/news/releases/2003/pr20/en/.

6. World Health Organization. Preventing Chronic Diseases: A Vital Investment: WHO Global Report. 2005. http://www.who.int/chp/ chronic_disease_report/contents/en/index.html.

7. Morgan MW, Zamora NE, Hindmarsh MF. An inconvenient truth: a sustainable healthcare system requires chronic disease prevention and management transformation. Healthc Pap. 2007;7(4):6-23.

8. Rothman AA, Wagner EH. Chronic illness management: what is the role of primary care? Ann Intern Med. 2003;138(3):256-261.

9. Epping-Jordan JE, Pruitt SD, Bengoa R, Wagner EH. Improving the quality of health care for chronic conditions. Qual Saf Health Care. 2004;13(4):299-305.

10. Health Canada. Primary Health Care and Health Care System Renewal. Ottawa: Health Canada; 2004.

11. Muldoon L, Rowan MS, Geneau R, Hogg W, Coulson D. Models of primary care service delivery in Ontario: why such diversity? Healthc Manage Forum. 2006;19(4):18-23.

12. Cretin S, Shortell SM, Keeler EB. An evaluation of collaborative interventions to improve chronic illness care. Framework and study design. Eval Rev. 2004;28(1):28-51.

13. Stevenson K, Baker R, Faroogi A, Sorrie R, Khunti K. Features of primary health care teams associated with successful quality improvement of diabetes care: a qualitative study. Fam Pract. 2001;18(1):21-26.

14. Sperl-Hillen JM, Solberg LI, Hroscikoski MC, Crain AL, Engebretson KI, O'Connor PJ. Do all components of the chronic care model contribute equally to quality improvement? Jt Comm J Qual Saf. 2004;30(6):303-309.

15. Vargas RB, Mangione CM, Asch S, et al. Can a chronic care model collaborative reduce heart disease risk in patients with diabetes? J Gen Intern Med. 2007;22(2):215-222.

16. Wagner EH, Austin BT, Davis C, Hindmarsh M, Schaefer J, Bonomi A. Improving chronic illness care: translating evidence into action. Health Aff (Millwood). 2001;20(6):64-78.

17. Suschnigg C. Reforming Ontario's primary health care system: one step forward, two steps back? Int J Health Serv. 2001;31(1):91-103.

18. Ministry of Health and Long Term Care, Primary Health Care Team. Billing and Payment Information for Family Health Groups. 2005. https://www oma org/PC/documents/BillingandPaymentInformationforFHGNov2005 pdf..
19. Gillett J, Hutchison B, Birch S. Capitation and primary care in Canada: financial incentives and the evolution of health service organizations. Int J Health Serv. 2001;31(3):583-603.

20. Shi L, Starfield B, Xu J. Validating the adult primay care assessment tool. J Fam Pract. 2001;50(2):161,E1.

21. Canadian Diabetes Association. Canadian Diabetes Association 2003 Clinical Practice Guidelines for the Prevention and Management of Diabetes in Canada. 2003.

22. Haley L. Regular eye care essential for diabetic patients. Med Post. 2002;38(41):11-12.

23. Canadian Cardiovascular Society. 1997 Consensus Conference on the Evaluation and Management of Chronic Ischemic Heart Disease. Can J Cardiol. 1998;14(Suppl C):1C-23C.

24. Wilt TJ, Bloomfield HE, MacDonald R et al. Effectiveness of statin therapy in adults with coronary heart disease. Arch Intern Med. 2004;12;164(13):1427-1436.

25. Liu P, Arnold JM, Belenkie I et al. The 2002/3 Canadian Cardiovascular Society consensus guideline update for the diagnosis and management of heart failure. Can J Cardiol. 2003;19(4):347-356.

26. Ontario Program for Optimal Therapeutics. Ontario Drug Therapy Guidelines for Chronic Heart Failure in Primary Care. 2000.

27. Hemmelgarn BR, Zarnke KB, Campbell NRC, et al. Canadian Hypertension Education Program, Evidence-Based Recommendations Task Force. The 2004 Canadian Hypertension Education Program recommendations for the management of hypertension: Part I-Blood pressure measurement, diagnosis and assessment of risk. Can J Cardiol. 2004;20(1):31-40.

28. N6 (NUD*IST 6) [computer program]. Cambridge, MA: International QSR; 2006.

29. Strauss A, Corbin J. Basics of Qualitative Research: Techniques and Procedures for Developing Grounded Theory. 2nd ed. Thousand Oaks, CA: Sage Publications; 1998.

30. Miles MB, Huberman MA. Qualitative Data Analysis. 2nd ed. Thousand Oaks, CA: Sage; 1994.

31. Miller WL, Crabtree B. Primary care research: a multimethod typology and qualitative road map. In: Doing Qualitative Research. Newbury Park, CA: Sage Publications; 1992.

32. Rittenhouse DR, Robinson JC. Improving quality in Medicaid: the use of care management processes for chronic illness and preventive care. Med Care. 2006;44(1):47-54.

33. Starfield B, Powe NR, Weiner JR et al. Costs vs quality in different types of primary care settings. JAMA. 1994;272(24):1903-1908.

34. Shi L, Starfield B, Xu J, Politzer R, Regan J. Primary care quality: community health center and health maintenance organization. South Med J. 2003;96(8):787-795.

35. Ohman-Strickland PA, Orzano AJ, Hudson SV, et al. Quality of diabetes care in family medicine practices: influence of nurse-practitioners and physician's assistants. Ann Fam Med. 2008;6(1):14-22.

36. Litaker D, Mion L, Planavsky L, Kippes C, Mehta N, Frolkis J. Physician-nurse practitioner teams in chronic disease management: the impact on costs, clinical effectiveness, and patients' perception of care. J Interprof Care. 2003;17(3):223-237.

37. Bailey $\mathrm{P}$, Jones L, Way D. Family physician/nurse practitioner: stories of collaboration. J Adv Nurs. 2006;53(4)381-391.

38. Bonner A, Rapp MP, Burl JB. Nurse practitioner/physician collaborative models of care. [comment]. J Am Med Dir Assoc. 2004;5(3):219220, author reply, 220-221.

39. Horrocks S, Anderson E, Salisbury C. Systematic review of whether nurse practitioners working in primary care can provide equivalent care to doctors. BMJ. 2002;324(7341):819-823.

40. Casalino L, Gillies RR, Shortell SM, et al. External incentives, information technology, and organized processes to improve health care quality for patients with chronic diseases. JAMA. 2003;289(4):434-441. 
41. Li R, Simon J, Bodenheimer T, et al. Organizational factors affecting the adoption of diabetes care management processes in physician organizations. Diabetes Care. 2004;27(10):2312-2316.

42. Schmittdiel JA, Shortell SM, Rundall TG, Bodenheimer T, Selby JV. Effect of primary health care orientation on chronic care management. Ann Fam Med. 2006;4(2):117-123.

43. Millett C, Car J, Eldred D, Khunti K, Mainous AG III, Majeed A. Diabetes prevalence, process of care and outcomes in relation to practice size, caseload and deprivation: national cross-sectional study in primary care. J R Soc Med. 2007;100(6):275-283.

44. Wang Y, O'Donnell CA, Mackay DF, Watt GC. Practice size and quality attainment under the new GMS contract: a cross-sectional analysis. Br J Gen Pract. 2006;56(532):830-835.
45. Bodenheimer T, Wang MC, Rundall TG, et al. What are the facilitators and barriers in physician organizations' use of care management processes? Jt Comm J Qual Saf. 2004;30(9):505-514.

46. Rundall TG, Shortell SM, Wang MC, et al. As good as it gets? Chronic care management in nine leading US physician organisations. BMJ. 2002;325(7370):958-961.

47. Solberg LI, Scholle SH, Asche SE, et al. Practice systems for chronic care: frequency and dependence on an electronic medical record. Am J Manag Care. 2005;11(12):789-796.

48. Green CJ, Fortin P, Maclure M, Macgregor A, Robinson S. Information system support as a critical success factor for chronic disease management: Necessary but not sufficient. Int J Med Inform. 2006;75(12):818-828.

\section{CHANCE-OF-ADDRESS FORM FAMIIYY MEDICINE}

Please complete this form and mail to the following address or fax to Annals Circulation at 913-906-6080:

Annals of Family Medicine, Circulation Department, 11400 Tomahawk Creek Pkwy, Leawood, KS 66211-2680

Check if member of sponsoring organization:

$$
\begin{array}{lc}
\square \text { AAFP } & \square \text { ABFM } \square \text { STFM } \square \text { ADFM } \\
\square \text { AFMRD } & \square \text { NAPCRG } \square \text { CFPC }
\end{array}
$$

ID number from label on your journal cover

OLD Information (Please print.)

Name

Company (if applicable)

Address (Street plus Apt or Ste)

\begin{tabular}{ll}
\hline City & State \\
\hline Country & Postal Code (9-digit ZIP for US) \\
\hline Telephone & Fax \\
\hline E-Mail &
\end{tabular}

NEW Information (Please print.)

\begin{tabular}{ll}
\hline Name \\
\hline Company (if applicable) \\
\hline Address (Street plus Apt or Ste) & \\
\hline Country & Postal Code (9-digit ZIP for US) \\
\hline Telephone & Fax \\
\hline E-Mail
\end{tabular}

